\title{
RANKL and TNF- $\alpha$-induced JNK/SAPK Osteoclastogenic Signaling Pathway was Inhibited by Caffeic Acid in RAW-D Cells
}

\author{
Ferry Sandra $^{1, *}$, Junita Briskila ${ }^{2}$, Ketherin ${ }^{2}$ \\ ${ }^{1}$ Department of Biochemistry and Molecular Biology, Division of Oral Biology, Faculty of Dentistry, Universitas Trisakti, \\ Jakarta, Indonesia \\ ${ }^{2}$ Faculty of Dentistry, Universitas Trisakti, Jakarta, Indonesia
}

\begin{abstract}
Caffeic acid, a natural substance found majorly in fruits, grains, and herbs, is known to have therapeutic benefits. One of which is to inhibit bone resorption by targeting osteoclastogenesis through inhibition of the Cathepsin K, p38 Mitogenactivated Protein Kinase (MAPK), Nuclear Factor of Activated T-cells c1 (NFATc1) and Nuclear Factor $\kappa B(N F \kappa B)$. Besides p38 MAPK, the c-Jun N-terminal kinase (JNK)/stressactivated protein kinases (SAPK), another member of MAPK family, has been reported to play important roles in osteoclastogenesis. Hence, current study was undertaken in order to investigate mechanism of Caffeic Acid towards JNK/SAPK pathway. Tartrate Resistant Acid Phosphatase (TRAP) staining was performed on caffeic acid-treated and RANKL-TNFa-induced RAW-D cells. Western blot analysis was performed to detect JNK/ SAPK and phosphorylated-JNK/SAPK. Protein bands were quantified and statistically analyzed. Treatment of $10 \mu \mathrm{g} / \mathrm{mL}$ Caffeic Acid inhibited $20 \mathrm{ng} / \mathrm{mL}$ RANKL and $1 \mathrm{ng} /$ $\mathrm{mL}$ TNFa-induced RAW-D differentiation into $\mathrm{TRAP}^{+}$osteoclast-like polynuclear cells. Induction of $20 \mathrm{ng} / \mathrm{mL}$ of RANKL and $1 \mathrm{ng} / \mathrm{mL}$ of TNF $\alpha$ for 0.2 or 1 hour, significantly increase phosphorylation of JNK/SAPK as compared with control. Treatment of $10 \mu \mathrm{g} / \mathrm{mL}$ Caffeic Acid significantly inhibited the $20 \mathrm{ng} / \mathrm{mL}$ of RANKL and $1 \mathrm{ng} / \mathrm{mL}$ of TNF $\alpha$-induced phosphorylation of JNK/SAPK. Taken together, Caffeic Acid could inhibit the RANKL and TNF $\alpha$-induced osteoclastogenesis through JNK/SAPK.
\end{abstract}

Keywords : Caffeic Acid, RANKL, TNF, RAW-D cells, osteoclastogenesis, JNK, SAPK

\section{INTRODUCTION}

Receptor Activator of Nuclear Factor $\kappa \mathrm{B}$ Ligand (RANKL) and Tumor Necrosis Factor (TNF) $\alpha$ have been shown to induce osteoclastogenesis effectively in RAW-D cells (Kukita, et al., 2004). Several second messengers and transcription factors of osteoclastogenic pathway induced by RANKL and TNF $\alpha$ in RAW-D cells have been reported, including TNF Receptor Associated Factor 6
(TRAF6) (Sandra, et al., 2013) and Nuclear Factor of Activated T-cells c1 (NFATc1) (Kukita, et al., 2004). These messengers and factors were shown to be important in osteoclastogenesis, hence inhibition

Submitted: May 23, 2018

Revised: May 30, 2018

Accepted: June 7, 2018

*Corresponding author: ferrysandra@gmail.com 
of each factor could decrease number of osteoclastlike cells.

Inhibition of osteoclastogenesis has been investigated due to the potential of osteoclastogenesis in bone resorption. In dentistry, bone resorption could be occured in periodontitis (Bartold, et al., 2010) and ameloblastoma (Sandra, et al., 2005). In dental implant treatment, osteoclastogenesis should also be controlled and minimized so that the implant could be intact and functionally supported in articular bone (Shannon, et al., 2011). Osteoprotegerin (OPG) as an agent to provide the osteoclastogenic inhibition, also binds with tumor necrosis factor-related apoptosisinducing ligand (TRAIL). Therefore, OPG also provides an inhbition of TRAIL-induced apoptosis in ameloblastomas (Sandra, et al., 2006). The concept of OPG was then used for the development of a new agent, denosumab (Hamdy, 2008). Other alternatives have been investigated as well, such as materials derived from natural resources, including herbs (Ming, 2013).

Caffeic Acid, one of the most common phenolic acids frequently found in fruits, grains, and herbs, has been widely studied because of it's ability to protect human cells from several diseases, such as cancer (Sandra and Sidharta, 2017), Alzheimer (Habtemariam, 2017) and bone resorption (Sandra, et al., 2011, Sandra, et al., 2013). Caffeic Acid fights osteosarcoma cells by inducing Caspases, including Caspase-8, -9 , and -3 , leading them into apoptosis (Sandra, et al., 2017). Caffeic Acid has also been reported to inhibit bone resorption by targeting osteoclastogenesis through inhibition of the Cathepsin K, NFATc1 (Tang, et al., 2006) and Nuclear Factor $\kappa B$ (NFкB) (Sandra, et al., 2011). Recently we reported that Caffeic Acid inhibits RANKL and TNF $\alpha$-induced p38 Mitogen-activated Protein Kinase (MAPK) osteoclastogenic pathway in RAW-D cells (Sandra and Ketherin, 2018). Besides p38 MAPK, the c-Jun N-terminal kinase (JNK), also referred as stress-activated protein kinases (SAPK), is another member of MAPK family that has been reported to play important roles in many different intracellular signaling pathways and control several functions including cell proliferation, differentiation, transformation, apoptosis, migration, and cytoskeletal integrity (Nishina, et al., 2004). Hence, this study was undertaken in order to investigate mechanism of Caffeic Acid towards JNK/SAPK pathway.

\section{MATERIALS AND METHODS}

\section{Cell Culture}

RAW-D cells were cultured in $\alpha$-MEM (GIBCO-BRL, Grand Island, NY, USA) with $10 \%$ FBS (Biosource, Camarillo, CA, USA) at $37^{\circ} \mathrm{C}$ in a humidified incubator with $5 \% \mathrm{CO}_{2}$.

\section{in vitro Osteoclastogenesis}

Six thousand RAW-D cells were treated with $10 \mu \mathrm{g} / \mathrm{mL}$ Caffeic Acid (Wako, Osaka, Japan), 2 hours prior to the osteoclastogenic induction of $20 \mathrm{ng} / \mathrm{mL}$ RANKL (PeproTech, London, UK) and $1 \mathrm{ng} / \mathrm{mL}$ TNF $\alpha$ (Roche Molecular Biochemicals, Mannheim, Germany). After 3 days, Tartrate Resistant Acid Phosphatase (TRAP) staining was performed using Leukocyte Acid Phosphatase Kit (Sigma-Aldrich, St. Louis, MO, USA). TRAP ${ }^{+}$ polynuclear cells (PNCs) were documented under an inverted microscope.

\section{Western Blot}

Cells were lysed using buffer containing $10 \mathrm{mM}$ Tris buffer (pH 7.4), $150 \mathrm{mM} \mathrm{NaCl}$, $1 \%$ Triton-X100 and protease inhibitor cocktail (Sigma-Aldrich). Protein was separated using sodium dodecyl sulfate (SDS)-polyacrylamide gel electrophoresis and transferred to a nitrocellulose membrane (Bio-Rad, Hercules, CA, USA). After transferring to membrane, the membrane was blocked with 5\% skim milk in phosphate buffer saline (PBS) (pH 7.4). Then the membrane was probed with 1:1000 diluted rabbit polyclonal antiphospho-JNK/SAPK MAPK (Thr183/Tyr185) antibody (Cell Signaling Technology, Danvers, 
MA, USA). The secondary antibody was 1:2000 diluted horseradish peroxidase-conjugated donkey anti-rabbit antibody (Cell Signaling Technology). The bound antibodies were visualized using Immun Star HRP Chemiluminescent Kit (Bio-Rad). Membrane was then stripped with Seppro stripping buffer (Sigma-Aldrich), blocked with 5\% skim milk in PBS, probed with rabbit polyclonal anti-SAPK/ JNK (Cell Signaling Technology), bound with same secondary antibody and visualized with the chemiluminescent kit. All visualized bands were captured using Alliance 4.7 (UVItech, Cambridge, UK) and quantified using UVIband software (UVItech, Cambridge, UK).

\section{Statistical Analysis}

Analyses were performed using IBM SPSS for Windows version 20.0 (IBM Corp., Armonk, NY, USA). T-test was used to determine the statistical differences between the means of experiments. A probability value $<0.05$ was considered to be statistically significant.

\section{RESULTS}

\section{RANKL and TNFa-induced Osteoclastogenesis was Inhibited by Caffeic Acid}

As shown in Figure 1B, $20 \mathrm{ng} / \mathrm{mL}$ RANKL and $1 \mathrm{ng} / \mathrm{mL}$ TNF $\alpha$ successfully induced differentiation of RAW-D cells into TRAP ${ }^{+}$osteoclast-like PNCs.
Treatment of $10 \mu \mathrm{g} / \mathrm{mL}$ Caffeic Acid inhibited $20 \mathrm{ng} / \mathrm{mL}$ RANKL and $1 \mathrm{ng} / \mathrm{mL}$ TNF $\alpha$-induced RAW-D differentiation into $\mathrm{TRAP}^{+}$osteoclast-like PNCs (Figure 1C).

Caffeic Acid Inhibited RANKL and TNFainduced Phosphorylation of JNK/SAPK in RAW-D Cells

Induction of $20 \mathrm{ng} / \mathrm{mL}$ of RANKL and $1 \mathrm{ng} / \mathrm{mL}$ of TNF $\alpha$ for 0.2 or 1 hour, significantly ( $p=0,000$, $\mathrm{T}$ test) increase phosphorylation of JNK/SAPK as compared with control (Figure 2). Treatment of 10 $\mu \mathrm{g} / \mathrm{mL}$ Caffeic Acid significantly ( $p=0,000, T$ test) inhibited the $20 \mathrm{ng} / \mathrm{mL}$ of RANKL and $1 \mathrm{ng} / \mathrm{mL}$ of TNF $\alpha$-induced phosphorylation of JNK/SAPK.

\section{DISCUSSION}

Osteoclast derived from hematopoietic monocyte precursors that balance the function of skeletal modeling and repair through complex pathways. This resorbing cell can be resulted under the regulation of critical factors, RANKL and OPG (Boyce and Xing, 2008). The RANKRANKL signaling pathway activates a series of TRAFs and can lead to the activation of nuclear factors and second messengers, such as JNK/SAPK (Hyeon, et al., 2013). Among the nuclear factors, activated $\mathrm{NF \kappa B}$ will also promote the inflammatory osteolysis (Lin, et al., 2017).
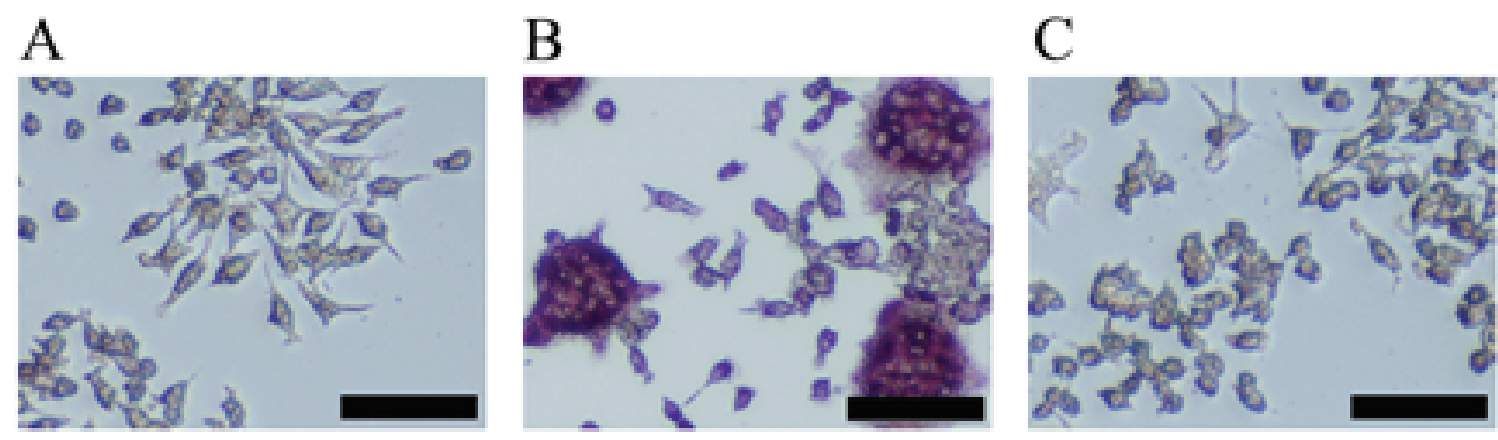

Figure 1. RANKL and TNFa-induced osteoclastogenesis was inhibited by caffeic acid in RAW-D cells. A: Untreated RAW-D cells. B: $20 \mathrm{ng} / \mathrm{mL}$ RANKL and $1 \mathrm{ng} / \mathrm{mL}$ TNF $\alpha$-induced RAW-D cells. C: RAW-D cells were treated with 10 $\mu \mathrm{g} / \mathrm{mL}$ caffeic acid followed by induction of $20 \mathrm{ng} / \mathrm{mL}$ RANKL and $1 \mathrm{ng} / \mathrm{mL}$ TNF $\alpha$. Bar: $100 \mu \mathrm{m}$. 


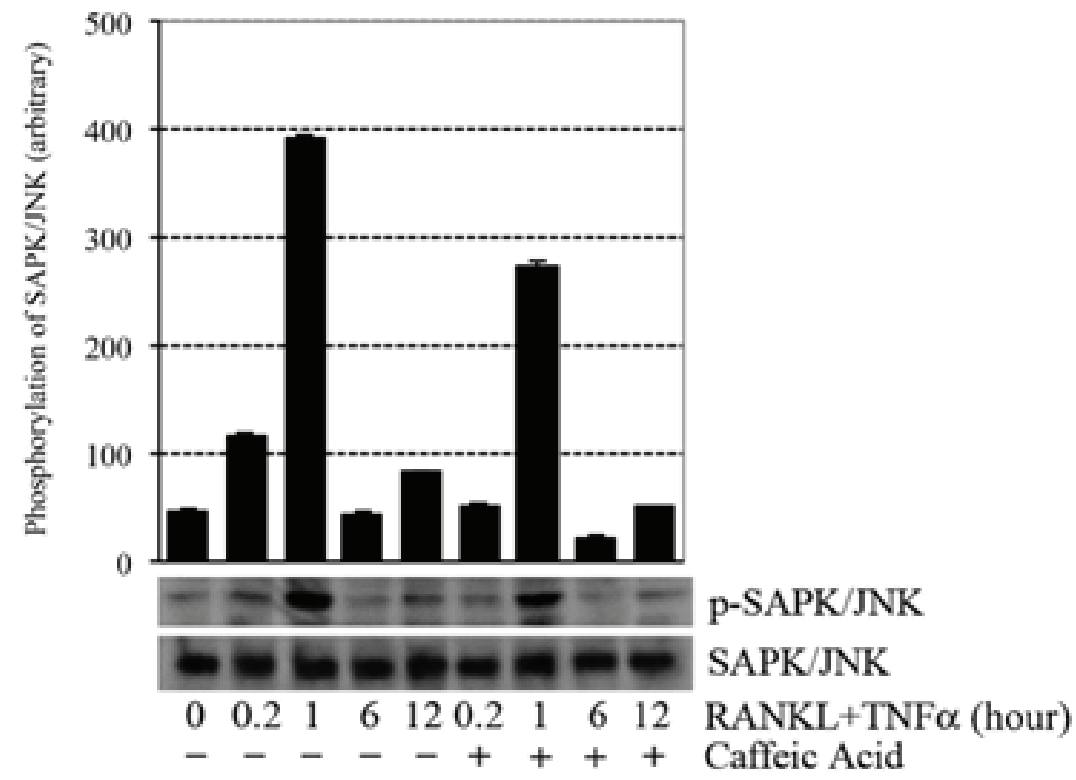

Figure 2. Caffeic acid inhibited RANKL and TNF $\alpha$-induced phosphorylation of JNK/ SAPK in RAW-D cells. RAW-D cells were treated with/without $10 \mu \mathrm{g} / \mathrm{mL}$ caffeic acid and induced with/ without $20 \mathrm{ng} / \mathrm{mL}$ of RANKL and $1 \mathrm{ng} / \mathrm{mL}$ of $\mathrm{TNF} \alpha$ for $0,0.2,1$, 6 and 12 hours. Cells were lysed and subjected to immunoblotting assay using anti-JNK/SAPK and anti-phosphorylated JNK/ SAPK antibodies. Data represent a typical result from 3 independent experiments.
Previous study has shown that caffeic acid did not significantly affect the expression of TRAF6 (Sandra, et al., 2013), but significantly inhbited the expression of p38 MAPK (Sandra, et al., 2018), as well as NFkB (Sandra, et al., 2011) in RANKL and $\mathrm{TNF} \alpha$-induced RAW-D cells. Multiple studies have associated RANKL-mediated osteoclastogenesis with JNK/SAPK. A correlation between the osteoclast differentiation and RANKL-induced JNK/SAPK activation has been established, suggesting that $\mathrm{JNK}$ is a strong key that regulates osteoclastogenesis (Islam, et al., 2007).

In the present study, RANKL and TNF $\alpha$ induced formation of $\mathrm{TRAP}^{+}$PNCs, meanwhile treatment of caffeic acid significantly inhibited the formation of RANKL and TNF $\alpha$-induced TRAP ${ }^{+}$ PNCs. The upregulated phosphorylation of JNK/ SAPK was confirmed in RANKL and TNF $\alpha$ induced RAW-D cell, meanwhile the treatment of caffeic acid clearly showed the significant inhibition of phosphorylated JNK/SAPK. These results suggests that despite p38 MAPK, caffeic acid might have ability to inhibit the risk of bone destruction through JNK/SAPK signaling pathway as well. Since other RANKL and TNF $\alpha$-induced osteoclastogenic signaling pathways have been reported, inhibition of caffeic acid should also be pursued further in those signaling pathways.

\section{CONCLUSION}

Taken together, caffeic acid could inhibit the RANKL and TNF $\alpha$-induced osteoclastogenesis through JNK/SAPK.

\section{REFERENCES}

Bartold, P.M., Cantley, M.D. and Haynes, D.R., 2010, Mechanisms and Control of Pathologic Bone Loss in Periodontitis, Periodontol., 2000, 53(1), 5569.

Boyce, B.F. and Xing, L., 2008, Functions of RANKL/ RANK/OPG in Bone Modeling and Remodeling, Arch. Biochem. Biophys., 473(2), 139-146.

Habtemariam, S., 2017, Protective Effects of Caffeic Acid and the Alzheimer's Brain: An Update, Mini Rev. Med. Chem., 17(8), 667-674.

Hamdy, N.A., 2008, Denosumab: RANKL Inhibition in The Management of Bone Loss, Drugs Today 
Indonesian Journal of Cancer Chemoprevention, June 2018 ISSN: 2088-0197

e-ISSN: $2355-8989$

(Barc)., 44(1), 7-21.

Islam, S., Hassan, F., Tumurkhuu, G., Dagvadorj, J., Koide, N., Naiki, Y., et al., 2007, Bacterial Lipopolysaccharide Induces Osteoclast Formation in RAW 264.7 Macrophage Cells, Biochem. Biophys. Res. Commun., 360(2), 346351.

Kukita, T., Wada, N., Kukita, A., Kakimoto, T., Sandra, F., Toh, K., et al., 2004, RANKL-induced DC-STAMP is a Key Transmembrane Molecule in Osteoclastogenesis, J. Exp. Med., 200(7), 941946.

Hyeon, S., Lee, H. , Yang, Y. and Jeong, W. , 2013, Nrf2 Deficiency Induces Oxidative Stress and Promotes RANKL-induced Osteoclast Differentiation, Free Radic. Biol. Med., 65, 789-799.

Lin, T.H., Pajarinen, J., Lu, L., Nabeshima, A., Cordova, L.A., Yao, Z., et al., 2017, NF-kB as a Therapeutic Target in Inflammatory-Associated Bone Diseases, Adv. Protein Chem. Struct. Biol., 107, 117-154.

Ming, L.G., Chen, K.M. and Xian, C.J., 2013, Functions and Action Mechanisms of Flavonoids Genistein and Icariin in Regulating Bone Remodeling, J. Cell. Physiol., 228(3), 513-521.

Nishina, H., Wada, T. and Katada, T., 2004, Physiological Roles of SAPK/JNK Signaling Pathway, J. Biochem., 136(2), 123-126.

Sandra, F., Hendarmin, L., Kukita, T., Nakao, Y., Nakamura, N. and Nakamura, S., 2005, Ameloblastoma Induces Osteoclastogenesis: A Possible Role of Ameloblastoma in Expanding in the Bone, Oral Oncol., 41(6), 637-644.

Sandra, F., Hendarmin, L. and Nakamura, S., 2006, Osteoprotegerin (OPG) Binds with Tumor Necrosis Factor-related Apoptosis-inducing
Ligand (TRAIL): Suppression of TRAIL-induced Apoptosis in Ameloblastomas, Oral Oncol., 42(4), 415-420.

Sandra, F., Kukita, T., Tang, Q.Y. and lijima, T., 2011, Caffeic Acid Inhibits NFkB Activation of Osteoclastogenesis Signaling Pathway, Indones. Biomed. J., 3(3), 216-222.

Sandra, F., Kukita, T., Muta, T. and lijima, T., 2013, Caffeic Acid Inhibited Receptor Activator of Nuclear Factor $k B$ Ligand (RANKL)-tumor Necrosis Factor (TNF) a-TNF Receptor Associated Factor (TRAF) 6 Induced Osteoclastogenesis Pathway, Indones. Biomed. J., 5(3), 173-178.

Sandra, F. and Sidharta, M.A., 2017, Caffeic Acid Induced Apoptosis in MG63 Osteosarcoma Cells through Activation of Caspases, Mol. Cell. Biomed. Sci., 1(1), 28-33.

Sandra, F., Hudono, K.F., Putri, A.A. and Putri, C.A.P., 2017, Caspase Inhibitor Diminishes Caffeic Acidinduced Apoptosis in Osteosarcoma, Indones. Biomed. J., 9(3), 160-164.

Sandra, F. and Ketherin, 2018, Caffeic Acid Inhibits RANKL and TNF-a-induced Phosphorylation of p38 Mitogen-activated Protein Kinase in RAW-D Cells, Indones. Biomed. J., in press.

Shannon, J., Shannon, J., Modelevsky, S. and Grippo, A.A., 2011, Bisphosphonates and Osteonecrosis of The Jaw, J. Am. Geriatr. Soc., 59(12), 2350 2355.

Tang, Q.Y., Kukita, T., Ushijima, Y., Kukita, A., Nagata, K., Sandra, F., et al., 2006, Regulation of Osteoclastogenesis by Simon Extracts Composed of Caffeic Acid and Related Compounds: Successful Suppression of Bone Destruction Accompanied with Adjuvant-induced Arthritis in Rats, Histochem. Cell. Biol., 125(3), 215-225. 